\title{
CB Research Square \\ Impact of online Internet Training on the Prevention and Control of the Novel Coronavirus Pneumonia
}

Xiaoli Wang

Yancheng the 3rd Hospital affiliated to Southeast University https://orcid.org/0000-0002-9979-5127

Haiyan Zhang

Yancheng the 3rd Hospital affiliated to Southeast University

Hongmei Xu

Yancheng the 3rd Hospital affiliated to Southeast University

Yao Wang

Nantong University Medical School

Ping Wang ( 491180993@qq.com)

\section{Research article}

Keywords: online internet training, novel coronavirus, pneumonia, nosocomial infection, prevention and control

Posted Date: July 2nd, 2020

DOI: https://doi.org/10.21203/rs.3.rs-35002/v1

License: (c) (i) This work is licensed under a Creative Commons Attribution 4.0 International License. Read Full License 


\section{Abstract \\ Background}

To observe the impact of online internet training on the prevention and control of the novel coronavirus pneumonia, and to supply clinical evidence for an effective safety training model for emergent public safety situations.

\section{Methods}

A total of 2,080 medical technicians of the Third People's Hospital of Yancheng, affiliated to Southeast University, were enrolled and divided into two groups based on the training mode (online vs. routine). They were evaluated based on the rate of excellence in five aspects: medical technicians' prevention and control, patient management, disinfection, medical waste disposal, and hand hygiene. A questionnaire was used to check the theoretical knowledge of both groups of the prevention and control of the new coronavirus pneumonia.

\section{Results}

The online training group had a higher excellence rate for medical technicians' prevention and control, patient management, disinfection, and medical waste disposal than the control group $(p<0.05)$. However, there was no statistically significant difference in hand hygiene assessment between the two groups. Based on the self-made questionnaire star-based survey, the online training group was more informed than the control group on the theoretical knowledge of the new coronavirus pneumonia.

\section{Conclusion}

Online training can effectively and safely improve the awareness regarding the infection-related knowledge and compliance of preventive measures. Thus, it should be implemented in hospitals to minimize the risk of cross-transmission among people.

\section{Background}

The new type of coronavirus pneumonia is transmitted through respiratory droplets, touch, and aerosol. It spreads quickly, causing severe health issues and has a high rate of mortality. The inability to control the transmission of this nosocomial infection can translate into a widespread viral infection, making patients severely sick, thus increasing the difficulty of treatment. The medical staff can use their medical knowledge to restrict the transmission of nosocomial infection during treatment; thus, it is critical to train the medical technicians. Generally, the training methods for the medical staff in hospitals include centralized teaching, retraining of the departments, and intranet-based distribution of the relevant training documents. These routine training methods apply to this new coronavirus outbreak, where crowd aggregation leads to an increased risk of close contact transmission. In recent years, online training has become a widely adopted learning method. Several educational institutions and network media use it as a teaching platform. In this study, we compared the efficiency of online training against the routine training methods in restricting the transmission of pneumonia due to the new coronavirus infection during the epidemic period.

\section{Methods}

\section{Clinical Materials}

In this study, the complete medical and technical staff of the Third People's Hospital of Yancheng, China, affiliated to the Southeast University, was divided into two groups, based on the training mode (online or routine). The online training group was 
comprised of 370 subjects, who received online training combined with the routine training, and the control group included 1,910 subjects who received the routine training. The reasons for subject withdrawal included sick leave, to provide aid to Hubei, and the shift system. Thus, 288 subjects received online training, and 1,566 subjects received routine training as a part of the control group. All subjects met the following inclusion criteria: (1) complete participation in the training; (2) all subjects were single-blinded for participation in the training and assessment. The study complied with the relevant guidelines and was examined and approved by the Ethics Committee of the hospital.

\section{Methods}

All subjects, who met the inclusion criteria, participated in the study under the unified arrangements of the hospital. The respective training modules were published in an intranet-based format. The training was conducted by the respective departments as a unit, with the director of the department and the head nurse as the point of contact, and the backbone members of the department conducting the training. The online training group subjects participated in the "Tencent Conference" platform, a type of teleconferencing, to receive appropriate knowledge and training and to resolve their queries, along with creating a WeChat "Nosocomial infection group," which served as a collective discussion platform for sharing and reviewing learning materials for self-preparation.

\section{Evaluation Methodology}

\section{Evaluation of the effectiveness of training}

The five aspects, which were compared between the two groups by regular supervision included (a) prevention and control excellence rate, (b) patient management excellence rate, (c) environmental disinfection quality excellence rate, (d) medical waste disposal excellence rate, and (e) hand hygiene assessment. Each of these five factors was evaluated on a score of 100 points with a score of $\geq 85$ points was considered excellent. We calculated $\geq 85$ points as the percentage of the total number of people in each group.

The specific assessment criteria were as follows:

(a) Excellent rate of prevention and control by the medical staff: all diagnosis and treatment sites should be equipped with sufficient number of appropriate protective equipment; strict implementation of hand hygiene; medical protective masks should be chosen according to the size of the face and airtight performance should be tested; protective gear should be replaced once every $4 \mathrm{~h}$, and latex gloves should be worn if required; Wearing of proper protective equipment should be strictly implemented; two different areas should be set up for removing the protective gear: the outer protective clothing should be removed in the first area, such as goggles, protective face screen, isolation clothes, outer gloves, and shoe covers, and the inner protective clothing, such as inner gloves, protective masks, and hats in the second area; the masks should not be removed in the contaminated areas; the protective clothing should be rolled from inside-out into the yellow garbage bag; and the standards for the replacement of protective equipment should be strictly implemented.

(b) Patient management excellence rate: each outpatient entrance should be equipped with ethanol and hydrogen peroxide as quick-drying hand disinfectants, the patients and their escorts should be given masks and provided appropriate guidance on how to wear them correctly; patients should have no accompanied guests as well as no visitors; good ventilation should be maintained and regular cleaning along with disinfection should be done; suspected or confirmed patients should have dedicated medical equipments, such as a stethoscope, thermometer, and other nursing supplies, if limited quantities are available, then standardized cleaning and disinfection procedures should be performed after each use; wards should be cleaned and disinfected routinely as the patients are transferred out according to the medical institutions' disinfection technical specifications for the final treatment of contact environment; medical waste, collected from either suspected or confirmed patients should be managed and disposed as per guidelines for the disposal of infectious medical waste.

(c) Excellent rate of environmental disinfection quality: the air in relevant departments, hands of the medical personnel, the surface of objects, the disinfectant in use, dialysate and dialyzed water, etc. should be sampled and monitored. Sampling methods and monitoring of results were done in accordance with the Technical Specification for Disinfection in Medical 
Institutions (WS/T367-2012), the Standard for Disinfection and Sanitation in Hospitals (GB15982-1995), the Standard for Monitoring the Effect of Disinfection and Sterilization in Jiangsu Hospitals, the Water for Hemodialysis and Related Treatment (YY0572-2015), and the Technical Management Standard for Blood Purification in Jiangsu Province.

(d) Excellent rate of medical waste disposal: the concentration of chlorine in the disinfectant used for the cleaning of the temporary storage points and special tools of medical waste should be 1000-2000 mg/L [1]. Additionally, the classification of medical waste, its collection and centralized disposal, harmless treatment, standardized storage and transportation, standardized handover of disposal companies, etc. should be maintained.

(e) Hand hygiene assessment: This assessment was done by the inspector according to the "hospital hand hygiene inspection qualified standard" score.

The above assessments were done once a week, for a total of 7 weeks. The average score was considered as the final score.

\section{Cognitive assessment of knowledge on infectious diseases and their containment}

Both the online training group and the control group were provided with a questionnaire to examine their theoretical knowledge on infectious diseases and suitable measures to restrict their transmission.

\section{Statistics}

The data was analyzed using SPSS 25.0 software, normal distribution was expressed as mean \pm standard deviation $(X \pm S)$. The results of both groups were compared using the t-test, and the counting data were compared using the chi-squared test. A $p$-value $<0.05$ was considered statistically significant.

\section{Results}

\section{Comparison of General information}

No statistically significant difference in age, sex, and education for all medical technicians, who participated in the training were observed $(p>0.05$; Table 1$)$

Table 1

Comparison of General Data

\begin{tabular}{|lllll|}
\hline & Online training group $(\mathrm{n}=\mathbf{2 8 8})$ & Routine group $(\mathbf{n = 1 5 6 6 )}$ & $\mathrm{X}^{2} / \mathrm{t}$ & $\boldsymbol{p}$ \\
\hline Age $(\mathrm{y})$ & $37.89 \pm 8.721$ & $36.73 \pm 10.452$ & 9.870 & 0.076 \\
\hline Sex $(\mathrm{n})$ & $61 / 227$ & $412 / 1154$ & 3.367 & 0.067 \\
\hline Scholar $(\mathrm{n})$ & $30 / 224 / 34$ & $173 / 1145 / 248$ & 3.403 & 0.182 \\
\hline Note: $p<0.05$ was statistically significant & & & \\
\hline
\end{tabular}

\section{Comparison of training effectiveness}

All indexes, such as prevention and control excellence rate, patient management excellence rate, environmental disinfection quality excellence rate, and medical waste disposal excellence rate, were higher in the online training group compared with the control group $(p<0.05)$. No significant difference was observed between both the groups in terms of hand hygiene assessment scores $(p>0.05$; Table 2). 
Table 2

Comparison of assessment scores between the Two Groups

\begin{tabular}{|c|c|c|c|c|c|c|c|c|c|}
\hline & $\begin{array}{l}\text { Online } \\
\text { training } \\
\text { group (n } \\
=288 \text { ) }\end{array}$ & $\begin{array}{l}\text { Control } \\
\text { group } \\
(n= \\
1566)\end{array}$ & $x^{2}$ & $p$ & & $\begin{array}{l}\text { Online } \\
\text { training } \\
\text { group (n } \\
=288 \text { ) }\end{array}$ & $\begin{array}{l}\text { Control } \\
\text { group } \\
(n= \\
1566)\end{array}$ & $\chi^{2} / t$ & $p$ \\
\hline $\begin{array}{l}\text { Medical personnel } \\
\text { prevention and } \\
\text { control excellence } \\
\text { rate }(\%)\end{array}$ & 69.8 & 62.8 & 5.195 & $0.023^{*}$ & $\begin{array}{l}\text { Medical } \\
\text { waste } \\
\text { disposal } \\
\text { excellence } \\
\text { rate (\%) }\end{array}$ & 61.1 & 52.6 & 7.168 & $0.007^{*}$ \\
\hline $\begin{array}{l}\text { Patient } \\
\text { management } \\
\text { excellence rate (\%) }\end{array}$ & 73.3 & 64.6 & 8.090 & $0.004^{*}$ & $\begin{array}{l}\text { Hand } \\
\text { hygiene } \\
\text { assessment } \\
\text { score }\end{array}$ & $\begin{array}{l}94.39 \pm \\
7.198\end{array}$ & $\begin{array}{l}94.01 \\
\pm 6.796\end{array}$ & 0.487 & 0.393 \\
\hline $\begin{array}{l}\text { environmental } \\
\text { disinfection quality } \\
\text { excellence rate (\%) }\end{array}$ & 63.9 & 57.5 & 4.046 & $0.044^{*}$ & $\begin{array}{l}\text { Theoretical } \\
\text { assessment } \\
\text { score }\end{array}$ & $\begin{array}{l}93.64 \pm \\
3.724\end{array}$ & $\begin{array}{l}90.10 \\
\pm 3.970\end{array}$ & 4.745 & $0.000^{*}$ \\
\hline
\end{tabular}

\section{Comparison of the basic theoretical knowledge on prevention and control of infections}

The online training group scored better in the questionnaire compared with the control group $(p<0.05 ;$ Table 2$)$.

\section{Discussion}

Human beings are a part of a high-risk society, where the elevated risk of public health emergencies, coupled with our social interactions, can magnify the situation in a short period, inducing a chain crisis [2]. The new coronavirus (COVID-19) pneumonia outbreak in 2020 has been one of the most rapid, widespread, and challenging public health emergencies in China, since the establishment of People's Republic of China. On February 11, 2020, the World Health Organization (WHO) named the disease caused by the virus as COVID-19 [3]. In this unprecedented crisis, raising risk awareness, developing knowledge on the prevention of health emergency risk, and adopting risk management technology has become the top priority. Since the previous ways of training, including large-scale gatherings to educate the medical personnel on how to avoid close-contact transmission, minimize the risk of hospital transmission, and prevent nosocomial infection are not feasible, we need to adopt ways to train a small number of people in an open, safe, and well-ventilated areas [4]. Therefore, our hospital adopted a modified version of the past training mode, where the control group participated in the study under the unified arrangement of the hospital, and the relevant training documents were provided in an intranet-based platform. The departmental director and the head nurse were the point of contact, and the backbone members conducted the training. The online training group received the relevant knowledge and documents on a "Tencent conference" platform. Both groups successfully received the knowledge and information on measures to restrict the transmission of the new coronavirus pneumonia, with a guaranteed zero infection rate in the whole hospital. Since online training methods were relatively new for the medical technicians, they were extremely interested. The training time, location flexibility, ease of learning, was relatively easier for the online training group compared with the control group. Moreover, one of the drawbacks of the conventional training method is the lack of communication, as sometimes the medical technicians are afraid to speak out their ideas, which was compensated by the online training method, based on the network platform, where medical staff could share their ideas. Online interaction, post-meeting messages, etc. promoted a multi-faceted improvement in the overall potential, and more importantly, avoided unnecessary crowd contact. The results of this study showed a statistically significant difference in the number of high scores related to the theoretical knowledge of infectious diseases and their transmission between the online training group and the control group. However, there was no significant difference in the scores for hand hygiene in this study, probably because hand hygiene is a daily habit, and thus the situation was not different in a pandemic. Due to the epidemiological characteristics of the new coronavirus pneumonia, medical staff prevention and control, patient management, environmental disinfection, and medical waste disposal 
have new updated requirements. Given these characteristics, we formulated a detailed training plan and assessment rules, supervised and scored, and found that in the online training group, the excellence rate of prevention and control, the excellence rate of patient management, the excellence rate of environmental disinfection quality, and the excellence rate of medical waste disposal were all higher than the control group. The use of network-based training had a high learning efficiency, a relaxed, interactive atmosphere, which was more conducive to learning, and thus, resulted in improved training. Several domestic reports have shown that the training of the clinical medical staff in hospital-related infections, and knowledge on their prevention and control is insufficient, and their training methods are very passive. The online training method conveys the same information more quickly and directly, enhancing the awareness and compliance of the medical technicians in restricting the infection, improving the awareness rate of the infectious diseases, and reducing the spread of the infection, along with avoiding crowd aggregation and reducing the risk of cross-contact transmission [5].

\section{Conclusion}

The outbreak of the new coronavirus pneumonia imparts an emergent, unpredictable, serious impact on human health, which directly affects public health, economic development, and social stability. The ability to manage this emergent situation in a general hospital is essential to ensure hospital safety. Through the implementation of active, timely, and efficient management strategies against this public health emergency, the organization would be able to implement the preventive measures for occupational protection and to reduce the exposure risk in this pandemic situation.

\section{Abbreviations}

1. Coronavirus Disease 2019, COVID-19

2. World Health Organization, WHO

\section{Declarations}

\section{Ethics approval and consent to participate}

Signed informed consent forms were obtained from all participants. Participants were informed of their right to withdraw without negative consequences and confidentiality. The study received approval from the institutional review board of The Yancheng school of Clinical Medicine of Nanjing Medical University.

\section{Consent for publication}

I, Wang Xiaoli, give my consent for information about myself to be published in BMC Infectious Diseases, INFD-D-20-02034, corresponding author: Wang Ping, Email: 491180993@qq.com.

I understand that the information will be published without my name attached, but that full anonymity cannot be guaranteed.

I understand that the text and any pictures published in the article will be freely available on the internet and may be seen by the general public. The pictures and text may also appear on other websites or in print, may be translated into other languages or used for commercial purposes.

I have been offered the opportunity to read the manuscript.

\section{Availability of data and material}

The datasets used and/or analysed during the current study are available from the corresponding author on reasonable request.

\section{Competing interests}


The authors declare that they have no competing interests.

\section{Funding}

Not applicable.

\section{Authors' contributions}

WX and WP designed the research study, analyzed the data. WY wrote the paper. $\mathrm{ZH}, \mathrm{XH}$ gave a substantial contribute to the acquisition of data. All authors approved the final version.

\section{Acknowledgements}

Not applicable.

\section{References}

1. Xia X, Li W, Gao H, et al. Difficulties and Countermeasures of Staff Training in Non-Determined General Hospitals during the Epidemic of New Coronavirus Pneumonia. Chinese Journal of Nosocomial Infection. 2020;30(11):1640-4.

2. Wu Q, Yang W. Health emergency management. Beijing: People's Health Publishing House; 2013. p. 8.

3. World Health Organization. WHO Director-Generalanagement. Beijing: People's Health Publishing House; 2020. Available at: https://www.who.int/dg/speeches/detail/who-director-general-s-remarks-at-the-media-briefing-on -2019-ncov - on-11february-2020.

4. Li S, Zhao Z, Yao Y, et al. 2019 Training Program, Content and Criteria for Prevention and Control of Pneumonia Hospital Staff with New Coronavirus Infection. New Medicine. 2020;51(2):95-102.

5. Rosenthal VD, Rodrigues C, Alvarez-Moreno C, et al. Effectiveness of a multidimensional approach for revention of ventilator-associated pneumonia in adult intensive care units from 14 developing countries of four continents:findings of the International Nosocomial Infection Control Consortium. Critcare Med. 2012;40(12):3121-8.

\section{Tables}

Table 1: Comparison of General Data

\begin{tabular}{|lllll|}
\hline & Online training group $(\mathrm{n}=288)$ & Routine group $(\mathrm{n}=1566)$ & $\mathrm{X}^{2} / \mathrm{t}$ & $p$ \\
\hline Age $(\mathrm{y})$ & $37.89 \pm 8.721$ & $36.73 \pm 10.452$ & 9.870 & 0.076 \\
\hline Sex $(\mathrm{n})$ & $61 / 227$ & $412 / 1154$ & 3.367 & 0.067 \\
\hline Scholar $(\mathrm{n})$ & $30 / 224 / 34$ & $173 / 1145 / 248$ & 3.403 & 0.182 \\
\hline
\end{tabular}

Note: $p<0.05$ was statistically significant

Table 2: Comparison of assessment scores between the Two Groups 


\begin{tabular}{|c|c|c|c|c|c|c|c|c|c|}
\hline & $\begin{array}{l}\text { Online } \\
\text { training } \\
\text { group } \\
(n=288)\end{array}$ & $\begin{array}{l}\text { Control } \\
\text { group } \\
(n=1566)\end{array}$ & $c^{2}$ & $p$ & & $\begin{array}{l}\text { Online } \\
\text { training } \\
\text { group } \\
(n=288)\end{array}$ & $\begin{array}{l}\text { Control } \\
\text { group } \\
(n=1566)\end{array}$ & $c^{2} / t$ & $p$ \\
\hline $\begin{array}{l}\text { Medical } \\
\text { personnel } \\
\text { prevention } \\
\text { and control } \\
\text { excellence } \\
\text { rate (\%) }\end{array}$ & 69.8 & 62.8 & 5.195 & $0.023^{*}$ & $\begin{array}{l}\text { Medical } \\
\text { waste } \\
\text { disposal } \\
\text { excellence } \\
\text { rate (\%) }\end{array}$ & 61.1 & 52.6 & 7.168 & $0.007^{*}$ \\
\hline $\begin{array}{l}\text { Patient } \\
\text { management } \\
\text { excellence } \\
\text { rate }(\%)\end{array}$ & 73.3 & 64.6 & 8.090 & $0.004^{*}$ & $\begin{array}{l}\text { Hand } \\
\text { hygiene } \\
\text { assessment } \\
\text { score }\end{array}$ & $94.39 \pm 7.198$ & $94.01 \pm 6.796$ & 0.487 & 0.393 \\
\hline $\begin{array}{l}\text { environmental } \\
\text { disinfection } \\
\text { quality } \\
\text { excellence } \\
\text { rate (\%) }\end{array}$ & 63.9 & 57.5 & 4.046 & $0.044^{*}$ & $\begin{array}{l}\text { Theoretical } \\
\text { assessment } \\
\text { score }\end{array}$ & $93.64 \pm 3.724$ & $90.10 \pm 3.970$ & 4.745 & $0.000^{*}$ \\
\hline
\end{tabular}

Note $₫ p<0.05$ was considered statistically significant 